\title{
REPRESENTAÇÕES SOCIAIS SOBRE CRIATIVIDADE CONSTRUÍDAS POR PROFESSORES E ALUNOS
}

\author{
REPRESENTACIONES SOCIALES DE LA CREATIVIDAD CONSTRUIDAS POR PROFESORES E ALUMNOS
}

SOCIAL REPRESENTATIONS ABOUT CREATIVITY BUILD BY TEACHERS AND STUDENTS

\author{
TÂNIA SARDINHA VIEIRA \\ taniasvieira@gmail.com \\ Esc. Sec. José Estêvão - Aveiro
}

MARIA JOÃO COSTA PEREIRA

IAMT - Lisboa

\section{ANTÔNIA OLIVEIRA SILVA}

$U F P B-P B / B R$

Autor responsável: Vieira, Tânia Sardinha - taniasvieira@gmail.com

Dissertação de Mestrado em Família e Sistemas Sociais: "Representações sociais sobre criatividade construídas por professores e alunos no âmbito da disciplina de educação visual" apresentada ao Instituto Superior Miguel Torga, Coimbra, Dezembro de 2004

Artigo original

\section{RESUMO}

A criatividade é entendida como um potencial existente em qualquer indivíduo, que para ser desenvolvida necessita de condições e ambientes adequados, ocorrendo a criatividade numa relação constante entre o sujeito e o mundo que o circunda. A disciplina de Educação Visual (EV) é considerada no 3 Ciclo do Ensino Básico (3을) a disciplina que privilegia a criatividade, porém percepciona-se a existência de diferentes discursos e práticas sobre criatividade por parte de professores e alunos, na interface da dinâmica da sala de aula.

\section{RESUMEN}

La creatividad es entendida como un potencial existente en qualquer individuo, que para ser desarrollada necesita de condiciones y de hambientes adecuados, y que tiene lugar dentro de una interrelación constante entre el sujeto y su mundo circundante. La disciplina de Educação Visual (EV) - Arte Educación es considerada en el 3er Ciclo de Enseñanza Básica como la disciplina que privilegia la creatividad; sin embargo se puede percibir entre profesores y alumnos, diversos discursos teóricos y prácticas sobre la creatividad, en la interfase de la dinámica en la sala de clases. 


\begin{abstract}
Creativity is understood as an inner potential that any individual possesses and that, in order to be developed, needs appropriate conditions and context; creativity occurs in a constant relation between the individual and his surroundings. The Educação Visual (EV) - Drawing and Art Education - subject is considered to be, in the 3rd Cycle of the Basic Education (3rd.CBE), the subject that enhances creativity, tough we can notice the existence of different discourses and practices about creativity from both teachers and students within the classroom and its dynamics
\end{abstract}

PALAVRAS-CHAVE: Criatividade; Representações Sociais; Professor; Aluno; Educação Visual.

PALABRAS-LLAVE: Creatividad; Representaciones Sociales ; Profesor; Alumno; Arte Educación

KEYWORDS: Creativity; Social Representations; Teacher; Student; Drawing and

Art Education.

\section{INTRODUÇÃO}

Este estudo teve na sua origem a percepção da existência de diferentes discursos e práticas sobre criatividade por parte de professores e alunos, na interface da dinâmica da sala de aula. A Criatividade pela perspectiva da teoria das representações sociais possibilita a edificação de um conhecimento socialmente compartilhado; um conhecimento vinculado às construções sociais influenciadas pelas culturas (atitudes, estereótipos, crenças), pelos grupos e pelo tempo. Desta forma, as representações sociais estão estritamente associadas ao saber do senso comum e, principalmente, elas são produto de uma sociedade específica.

Para Moscovici (1978) as representações não são cópias fiéis ou mesmo reproduções do real, mas sim uma reconstrução desse real, que confere sentido aos comportamentos e prepara o indivíduo para a acção. Nesta perspectiva, Vala (2002, p.460) afirma que as representações sociais são "factores produtores de realidade", que modelam as respostas dos grupos sociais que as construíram e/ou onde vigoram, por se repercutirem na forma como interpretamos a realidade.
Em paralelo com a actividade representativa, o conceito de representação social remete-nos também para um nível de análise específico, o do social, como "uma forma de conhecimento, socialmente elaborada e partilhada, com um objectivo prático e contribuindo para a construção de uma realidade comum a um conjunto social" (JODELET, 1997, p.53). Desta forma, a análise das representações sociais privilegia o estudo dos elementos cognitivos que participam na construção da realidade social e, de igual forma, dos elementos dinâmicos implicados nesses processos de produção de significados bem como na orientação das comunicações e dos comportamentos (Moscovici, in PINTO, 2000, p.117).

Para Gilly (1997) o interesse essencial da noção de representação social para a compreensão dos fenómenos educativos é que ela dirija a atenção sobre o papel de conjuntos organizados de significações sociais no processo educativo. Este conceito oferece um novo caminho para a explicação dos mecanismos pelos quais factores especificamente sociais agem sobre o processo educativo e como influenciam os resultados e o próprio processo em si. 0 mesmo autor enfatiza que vários autores referem que, as situações educativas, para além de factores exter- 
nos como as relações entre a pertença a um certo grupo social, atitudes e comportamentos em relação à escola, o modo como o professor concebe o seu papel, também dizem respeito a níveis mais finos de análise relativos à comunicação pedagógica em sala de aula e à construção dos saberes.

O sistema escolar foi sempre objecto de vários discursos provenientes de diferentes grupos: políticos, agentes das instituições, alunos, professores, etc. Como afirma Gilly (1997, p.384),

"o campo educativo revela-se um campo privilegiado para ver como se constroem, evoluem e se transformam as representações sociais no seio de grupos sociais e para nos esclarecer sobre o papel destas nas relações destes grupos com o objecto da sua representação. Pode assim compreender-se por que razão os sistemas de representações são feitos de contradições".

Algumas das directrizes do Ministério de Educação (ME) sustentam um discurso de valorização das artes e da criatividade, apesar de no nosso sistema de ensino (quer pela prática pedagógica e discurso de muitos professores, quer pelas reorganizações curriculares implementadas pelo ME) se verificar o contrário - as artes e a criatividade, nas diversas áreas curriculares, são desvalorizadas e entendidas com um papel secundário, diminuindo desta forma a possibilidade de um crescimento integral.

No currículo do $3^{\text {o }}$ Ciclo do Ensino Básico (3ํㅡㄹ), a disciplina de Educação Visual é obrigatória nos 7ํㅜ e 8oanos, tornando-se opcional no 9o․ Esta disciplina é autónoma enquanto disciplina curricular e caracteriza-se pela orientação nítida para a Educação Artística e Estética, através da educação da percepção visual, da expressão livre não condicionada e do método de design, enquanto formas específicas de olhar o mundo e de nele intervir. A disciplina de E.V. não implica ou pressupõe uma abordagem sequencial dos conteúdos permitindo às diferentes escolas do país a gestão livre do currículo. Desta forma, o professor de E.V. pode planificar os conteúdos programáticos tendo em conta as características sócio-culturais e económicas do meio onde se encontra a leccionar. Esta autonomia da gestão curricular permite ao professor de
E.V. desenvolver, estimular e facilitar a criatividade dos seus alunos.

Verifica-se nas escolas a existência de diferentes discursos e práticas sobre a criatividade por parte de professores e alunos, tornando-se a escola um meio teórico que permite a construção de representações sociais. Para se ter acesso a estas representações sociais, a linguagem possui um papel fundamental, uma vez que ela é responsável pela codificação das representações que circulam no contexto social em que o indivíduo se encontra inserido, possibilitando a articulação deste com a rede de significados sociais. Ela é ainda responsável pela manutenção das objectivações comuns que circulam na vida quotidiana.

Assim sendo, esta investigação teve o objectivo de identificar, ou pelo menos intuir, as representações sociais sobre a criatividade, construídas por professores e alunos do 9 o ano do $3^{\circ}$ CEB no âmbito da disciplina de Educação Visual.

\section{ABORDAGEM METODOLÓGICA}

0 estudo, de carácter exploratório, fundamenta-se em dois domínios do conhecimento: teoria da criatividade e teoria das representações sociais, no campo da educação.

Tendo isto em consideração, a realização do presente estudo teve como pedra angular o discurso dos sujeitos que leccionam a disciplina de Educação Visual (EV) e daqueles que a frequentam ou frequentaram, pelo facto de EV ser considerada no $3^{\circ}$ CEB a disciplina que privilegia a criatividade.

Tendo isto em consideração, a realização do presente estudo teve como pedra angular o discurso dos sujeitos que leccionam a disciplina de Educação Visual (EV) e daqueles que a frequentam ou frequentaram, pelo facto de EV ser considerada no $3^{\circ}$ CEB a disciplina que privilegia a criatividade.

A amostra do estudo é constituída por 42 sujeitos distribuídos por dois grupos: Grupo I - 21 Professores de 
Educação Visual e Grupo II - 21 Alunos do 9o ano do 3o CEB. Os critérios para a inclusão dos sujeitos na amostra foram: todos os sujeitos aceitarem participar do estudo; todos os professores serem docentes da disciplina de Educação Visual, independentemente de se encontrarem a leccionar a disciplina no presente ano lectivo; todos os alunos serem do $9^{\circ}$ ano do $3^{\circ} \mathrm{CEB}$, independentemente de se encontrarem a frequentar a disciplina de EV no ano lectivo em questão. As variáveis sócio-demográficas consideradas são as indicadas no quadro abaixo.

\begin{tabular}{|c|c|c|c|c|c|c|c|}
\hline \multirow{2}{*}{ VARIÁVEIS } & \multicolumn{2}{|c|}{ Sexo } & \multicolumn{3}{c|}{ Idade } & \multicolumn{2}{c|}{ Categoria / Grupo } \\
\cline { 2 - 8 } & Feminino & Masculino & 14 a 17 & 28 a 35 & $>35$ & I- Professores & II - Alunos \\
\hline No & 25 & 17 & 21 & 11 & 10 & 21 & 21 \\
\hline Total & $60 \%$ & $40 \%$ & $50 \%$ & $26 \%$ & $24 \%$ & $50 \%$ & $50 \%$ \\
\hline
\end{tabular}

Quadro 1 / Variáveis Sócio-Demográficas

0 instrumento utilizado para recolha de dados foi o Teste da Associação Livre de Palavras (TALP), com o termo indutor: criatividade. Os dados obtidos por meio do TALP foram tratados pelo software Tri-deux Mots (CIBOIS, 1995) que utiliza o método da análise factorial de correspondências (AFC). Este método permite obter representações gráficas onde se podem detectar relações entre as variáveis fixas (variáveis sócio-demográficas) e as variáveis de opinião (que correspondem às respostas dos sujeitos).

A análise factorial de correspondências é uma técnica de análise de dados, desenvolvida nos anos sessenta, especialmente adequada à exploração e descrição de dados qualitativos e um dos mais potentes utensílios matemáticos para o tratamento de inquéritos (BOUROCHE e SAPORTA, 1990).

Na organização do material recolhido, procedeu-se inicialmente à elaboração de um dicionário referente às respostas associadas ao estímulo indutor (criatividade) com a participação de todas as palavras evocadas pelos 42 sujeitos (219 palavras de entrada). Essas palavras foram agrupadas mediante a similaridade semântica, com o intuito de evitar redundâncias e de torná-las estatisticamente significativas (92 palavras diferentes).
Posteriormente organizou-se uma tabela de dados constituída pelas variáveis de opinião (palavras) dispostas sobre linhas horizontais, codificadas em palavras agregadas a numerais referentes a cada uma das categorias/grupos da amostra (professores - 1, alunos - 2) e pelas variáveis fixas (sexo, faixa etária e grupo da amostra), registadas nas três primeiras colunas.

Os dados organizados foram submetidos ao software Trideux Mots, como já foi referido, que os processou analisando apenas as palavras com frequência de repetição mínima igual ou superior a três. Para a análise do material final deste processo foram consideradas as modalidades que obtiveram a contribuição por factor superior a duas vezes a média que corresponde às modalidades ou palavras que contribuíram com maior significação na construção dos factores.

Em termos genéricos a técnica de AFC explicita as correlações (positivas e negativas) existentes entre diferentes grupos, colocando em evidência os campos semânticos apreendidos pelas palavras associadas ao estímulo e a sua contribuição para a construção dos factores ou eixos que constituem o plano factorial. Esta análise evoca os princípios geradores e organizadores das diferenças entre opiniões ou entre as práticas (consensuais e/ou diferentes), permitindo ilustrar ou explicar empiricamente diferentes dinâmicas das representações sociais (DOISE, 1992).

A análise do gráfico é realizada a partir da leitura das modalidades (palavras evocadas) organizadas de maneira oposta segundo os factores F1 e F2. Esta técnica de AFC, mediante o recurso ao software Tri-deux Mots, coloca em relevo as relações de "atracção" e "repulsa" entre os componentes dos diferentes grupos. 0 programa calcula os valores próprios (ou característicos) associados aos eixos. Cada valor próprio permite calcular a quantidade de variância explicada pelo respectivo eixo.

Os resultados da análise encontram-se apresentados no gráfico que se apresenta a seguir. 


\section{ANÁLISE E COMENTÁRIOS DOS RESULTADOS}

A análise e comentários sobre as representações sociais elaboradas por estudantes e professores sobre a criatividade centrar-se-á no eixo que focaliza os processos e conteúdos a partir das representações sociais da criatividade em contexto educacional, decorrentes do Teste de Associação Livre de Palavras.

A aplicação do TALP originou um conjunto de 219 palavras de entrada para o estímulo indutor criatividade, reduzidas a 92 palavras por similaridade semântica. Este corpus de análise foi processado pelo software Tri-deux Mots.

Dos dados obtidos o factor 1, F1, explicou 86\% da variância total (explicada) das modalidades. Apesar de o valor da contribuição de F1 ser elevado, recorre-se a um outro factor, F2, para se conseguir uma representação gráfica no plano factorial (F1, F2). Com F1 e F2 obtém-se 95\% de variância explicada, pois a contribuição de F2 é de aproximadamente $9 \%$.

Considerou-se apenas as coordenadas F1 e F2; verificamos, por exemplo, que as projecções das modalidades "tensão1" e "trabalho1" têm as mesmas coordenadas pelo que estão representadas no gráfico pelo mesmo ponto do $4^{\circ}$ quadrante do plano factorial (F1 positivo e F2 negati- vo). Já as modalidades "diferença1" e "arte2" estão quase sobre o eixo F1 e em posições quase simétricas em relação a F2, estando "diferença1" no 1ํo quadrante (F1 e F2 positivos) e "arte2" no $2^{\circ}$ quadrante (F1 negativo e F2 positivo).

Os resultados explicitados no gráfico 1, apresentam a configuração da estrutura do campo de representação social sobre a criatividade.

No gráfico 1, observa-se no factor 1 (F1, negativo), que a criatividade foi associada pelos alunos do $9^{\circ}$ ano (49\%), faixa etária dos 14 aos 17 anos de idade, a imaginação, arte e trabalho. Nesse mesmo factor, no lado direito (positivo) encontram-se os professores de Educação Visual (51\%) que associaram criatividade a diferença, originalidade, imaginação e criar.

Neste sentido, as representações sociais construídas pelos estudantes e professores sobre criatividade foram ancoradas em aspectos psicológicos e sociais em que os sujeitos argumentam e discutem o quotidiano institucional e colocam as heranças histórico-culturais das suas realidades sociais, uma vez que o meio envolvente é de igual forma um meio teórico, onde circulam teorias sobre as grandes questões que os indivíduos se colocam e que são a expressão das respostas que souberam encontrar, o

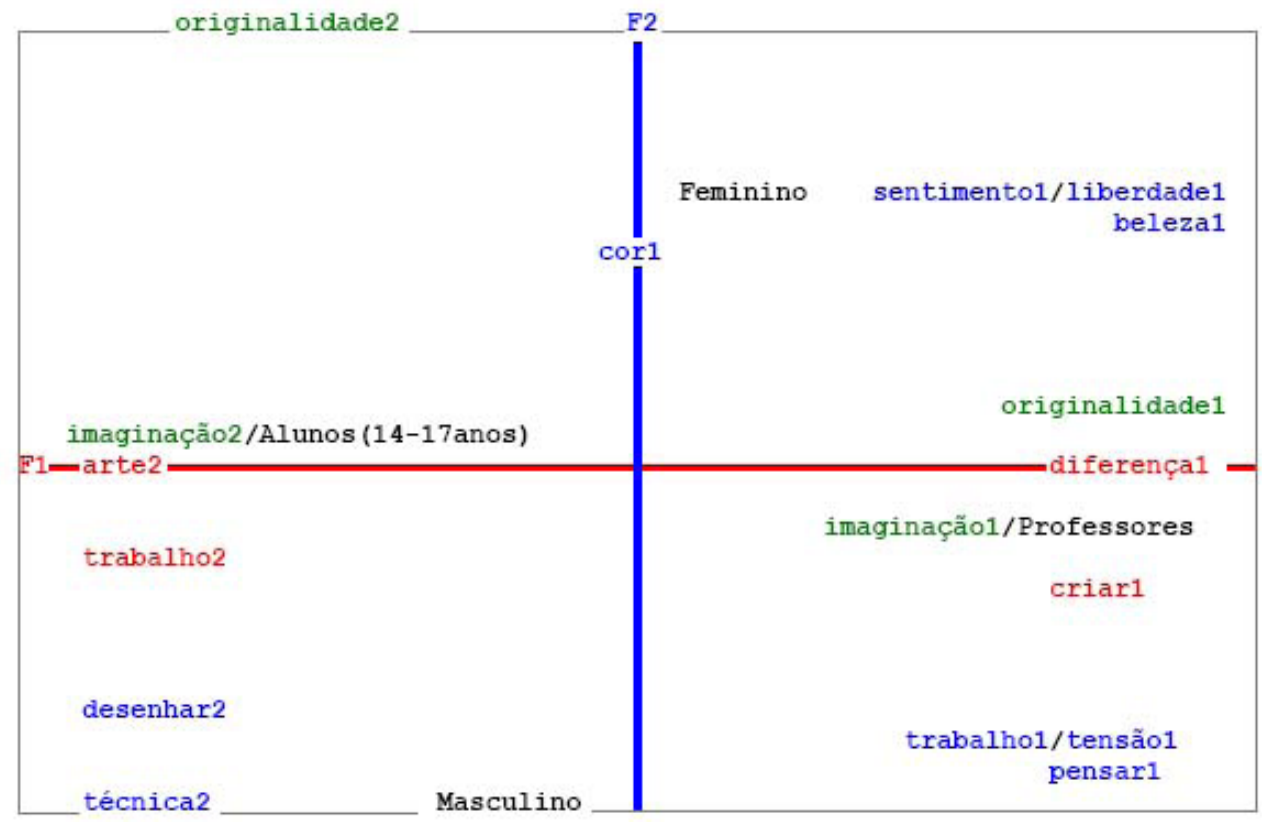

Legenda:

Factor $1=$ Vermelho

Factor 2 = Azul

Factor 1 e 2 = Verde

Gráfico 1 - Análise Factorial de Correspondências das Representações Sociais sobre Criatividade 
que representa uma nova concepção sobre o homem, as relações sociais e a estrutura social (VALA, 2002, p.465).

No que se refere ao factor 2, verifica-se no campo superior (F2, positivo), uma participação dos sujeitos do sexo feminino (59\%), nos dois grupos (professor de EV / aluno), para o qual criatividade encontra-se associada a originalidade, cor, sentimento, liberdade e beleza. Ainda no mesmo factor, no campo inferior (F2, negativo) encontram-se as representações elaboradas pelos actores sociais do sexo masculino (41\%), objetivadas pelos elementos sócio-cognitivos: desenhar, técnica, trabalho, tensão e pensar. Nessas representações sociais é possível identificar tipos de ancoragens psicológicas, sociais e psicossociais, de cunho abstractos com vertentes estéticas e psico-afetivas.

Observando-se o gráfico 1, destacam-se dois conjuntos de modalidades representados, em oposição, sobre o factor 1. No lado esquerdo do F1 encontra-se o campo semântico da criatividade, representado pelos alunos do $9^{\circ}$ ano, na faixa etária dos 14 aos 17 anos de idade. Para este grupo, criatividade é sinónimo de imaginação, arte e trabalho.

Ao analisarmos as imagens produzidas pelos alunos verificamos a relação próxima entre a imaginação e a arte, contendo estas uma dimensão subjectiva e relacionada com o pensamento abstracto. Porém, o trabalho é de igual forma objectivado pelos alunos. Pode subentender-se que as representações sociais sobre criatividade construídas pelos alunos são elaboradas no âmbito da disciplina de Educação Visual, na interface do pensamento abstracto (imaginação/arte) articulado com o pensamento concreto (trabalho). Nesta faixa etária e neste nível de formação académica, a imaginação e a arte concretizam-se na exploração de diversos materiais que se encontram subjacentes ao desenvolvimento de um determinado trabalho. Pode deduzir-se que apesar da sua conotação subjectiva, a imaginação e a arte, quando referidas pelos alunos, transportam consigo a concretização de um determinado pensamento e forma de expressão através da materialização dos mesmos, em resposta a uma determinada proposta de trabalho.
Sousa (2003) refere que a "questão central, geradora da diferença mais importante, é a de que a criatividade não pode ser ensinada, mas apenas facilitada, isto é, não se pode levar alguém a ser criativo dizendolhe ou mostrando-lhe o que deve fazer. A criatividade prende-se com a descoberta e expressão de algo que é tanto uma novidade para o indivíduo criador quanto para a realização em si mesma, com o conseguir expressar o que se tem dentro de si, com o tornar o complexo simples. 0 acto de explicar como algo foi inventado pode facultar, a quem o compreenda, a possibilidade de replicar esse invento, mas essa replicação já não pode ser considerada um acto criativo. 0 mesmo se verifica para qualquer aptidão humana, desde a inteligência à capacidade de exteriorizar sentimentos e emoções". Aquele acto pode, no entanto, ser profícuo na medida em que ilustre um "clique" criativo, onde, frequentemente, se estabelecem relações até então inimagináveis. Isto pode despertar na criança ou no jovem a capacidade de ousar.

Nesta perspectiva, o papel do professor passa, entre outras coisas, por facilitar, estimular, promover e criar as condições propícias ao desenvolvimento da criatividade dos alunos. E ao assumir esta atitude o professor/educador está, ele próprio, a assumir-se como criativo; provavelmente "só professores criativos, que praticam a criatividade, podem liderar processos de desenvolvimento da criatividade. Os rotineiros e conformistas acabam por arrasar todos os rebentos de imaginação, sensibilidade, iniciativa pessoal e criatividade, condenando os alunos à repetição, à rotina e ao conformismo" (Cabezas, in MARTINS, 2000, p.27).

No factor 1, no lado positivo, temos os professores de EV, que representam a criatividade por originalidade, diferença, imaginação e criação.

A criatividade deverá ser entendida como uma competência que implica, para além do processo de pensamento, outras características cognitivas. Slabbert (pp. 66-68, 1994), descreve cinco características que devem ser implementadas numa aula para promover a criatividade: a originalidade, fluência, selecção, elaboração e abertura mental. Originalidade como ser capaz de fazer um salto 
mental, quebrar com o óbvio podendo recorrerse ao método de analogias, fluência como a capacidade de gerar o maior número possível de ideias para a resolução de problemas (SLABBERT, 1994).

Ao analisar-se as representações dos professores de EV, originalidade, diferença, imaginação e criar, pode deduzir-se que originalidade, diferença e imaginação se encontram subjacentes a este processo de criar. Apesar de os autores referidos terem recorrido a outras metodologias de investigação, verifica-se no gráfico 1 que o campo representacional dos professores de EV refere um conjunto de representações que corroboram os resultados dos seus estudos.

Pode inferir-se que as representações sociais sobre criatividade construídas pelos professores são elaboradas na relação do pensamento abstracto (originalidade / imaginação) articulado com o pensamento concreto (criar / diferença). Desta forma, para os professores de EV, a criatividade implica, para além do processo de pensamento, outras características cognitivas, o que está em concordância com os estudos de Slabbert (1994).

No factor 2, o sexo feminino e masculino encontram-se em posições opostas. No campo representacional observa-se que o sexo feminino, como já foi referido anteriormente, representa criatividade por originalidade (alunas), cor, sentimento, liberdade e beleza (professoras de EV).

Csikszentmihalyi (2002) no seu trabalho sobre as experiências do fluir (a expressão óptima) descreve extensivamente as consequências da procura de desafios que combinem com as habilidades de um indivíduo. Afirma ainda que as pessoas envolvidas activamente em trabalhos criativos procuram experiências do fluir e que a criatividade resulta melhor sendo oriunda de estados como estes. Para Collins e Amabile (1999, p. 301) o poder da motivação intrínseca é tão forte que só de pensar em razões intrínsecas para realizar uma tarefa pode ser suficiente para impulsionar a criatividade nessa mesma actividade.

Apesar de as expressões motivação intrínseca e experiência do fluir não se encontrarem nas representações produzidas pelo sexo feminino, pode inferir-se que as representações originalidade, sentimento, cor, liberdade e beleza lhes são inerentes. Desta forma, pode concluirse que o sexo feminino objectiva a criatividade orientada para a auto-expressão, para uma liberdade individual e como qualidade de beleza, num quadro subjectivo e psicoafectivo.

A criatividade dos alunos do sexo masculino é objectivada com elementos (desenhar e técnica) da prática do quotidiano, inerentes à disciplina de Educação Visual. Os professores de EV do sexo masculino encontram-se associados a uma intensa actividade cognitiva. Desta forma, pode concluir-se que as representações sobre criatividade construídas pelos sujeitos do sexo masculino implicam todo um conjunto de experiências, de pesquisas diferenciadas valorizando o pensamento analítico, concreto, que envolve a criatividade.

Os dados obtidos no nosso estudo permitem-nos verificar a existência de diferentes representações dependendo do sexo ao qual se pertence. Apesar da utilização de metodologia diferenciada, estes dados corroboram os estudos de Collings e Smithers e os de Fryer (1999).

Esta Análise Factorial de Correspondências permite compreender, além das distâncias estabelecidas entre as representações, a frequência de palavras conforme apresentado no quadro 2 que mostra os valores das frequências absolutas e relativas (estas em \%), por ordem decrescente, das respostas evocadas e que foram encontradas a partir das contribuições para os factores.

Conforme os dados apresentados no quadro abaixo, relativamente a F1 a frequência das palavras imaginação e originalidade evocadas pelo grupo de professores de EV são reveladoras da sua importância, pois 23\% dos sujeitos referiram-nas como resposta ao estímulo criatividade. Quanto ao grupo de alunos, ainda neste factor, a palavra imaginação foi dita por $26 \%$ dos sujeitos em resposta ao mesmo estímulo. Já em F2, a palavra pensar foi referida por $20 \%$ dos professores e no que diz respeito aos alunos, originalidade e desenhar foram 


\begin{tabular}{|c|c|c|c|c|c|c|}
\hline FACTORES & PROFESSORES DE EV & $f$ & $\%$ & ALUNOS & $f$ & $\%$ \\
\hline \multirow{7}{*}{ Factor 1} & Imaginação1 & 78 & 23 & Imaginação2 & 96 & 26 \\
\hline & Originalidade1 & 75 & 23 & Desenhar2 & 77 & 21 \\
\hline & Diferença 1 & 48 & 14 & Arte2 & 52 & 14 \\
\hline & Criar1 & 45 & 13 & Trabalhar2 & 47 & 13 \\
\hline & Conhecimento1 & 33 & 10 & Pensar2 & 35 & 9 \\
\hline & Ideia1 & 30 & 9 & Material2 & 32 & 9 \\
\hline & Sentimento1 & 28 & 8 & Liberdade2 & 29 & 8 \\
\hline TOTAL & & 337 & 100 & & 368 & 100 \\
\hline \multirow{8}{*}{ Factor 2} & Pensar1 & 88 & 20 & Originalidade2 & 185 & 45 \\
\hline & Cor1 & 70 & 16 & Desenhar2 & 125 & 30 \\
\hline & Liberdade1 & 58 & 13 & Técnica2 & 76 & 19 \\
\hline & Sentimento1 & 58 & 13 & Elaborar2 & 24 & 6 \\
\hline & Beleza1 & 47 & 10 & ---- & -- & -- \\
\hline & Trabalho1 & 46 & 10 & ---- & -- & -- \\
\hline & Tensão1 & 46 & 10 & $\begin{array}{ll}---- \\
\end{array}$ & -- & -- \\
\hline & Material1 & 36 & 8 & ---- & -- & -- \\
\hline TOTAL & & 449 & 100 & & 410 & 100 \\
\hline
\end{tabular}

Quadro 2 / Distribuição da Frequência (f) das palavras mais evocadas pelos grupos professores e alunos em F1 e F2

referidas, respectivamente, por $45 \%$ e $30 \%$ destes sujeitos. Ao analisarmos este quadro verificamos que existem representações sociais compartilhadas intra e intergrupo em que a imaginação foi fortemente evocada por ambos os grupos.

\section{CONSIDERAÇÕES FINAIS}

De acordo com os dados acima no que respeita aos professores de EV, o sexo feminino enfatiza as características abstractas e subjectivas da criatividade, enquanto o sexo masculino valoriza o pensamento analítico e concreto, associado a uma intensa actividade cognitiva. Porém, independentemente do sexo, os professores de EV objectivam a criatividade num plano que não é necessariamente enquadrado no âmbito da disciplina de Educação Visual. Diferentemente deste grupo, os alunos referem a criatividade contextualizada com as práticas pedagógicas da disciplina de EV, que têm subjacente a imaginação e a originalidade como inerentes às expressões artísticas, enfatizando o pensamento que compreende a materialização e concretização de trabalhos.
Se a escola ocupa um lugar de destaque no desenvolvimento das potencialidades humanas, é importante que também promova o desenvolvimento da criatividade e do pensamento criativo em cada um dos alunos, criando condições físicas, técnicas e pedagógicas que possam activar este processo de aprendizagem, com vista à sua formação integral. 0 acto educativo implica uma relação equilibrada entre o sujeito que vai ensinar e o sujeito que vai aprender. Entendendo-se, assim, o processo de ensino-aprendizagem não como uma relação unívoca, mas sim bilateral, em que o professor e os alunos trocam experiências e co-constroem o conhecimento interagindo com o meio. 0 nosso sistema de ensino tem negligenciado esta relação do acto educativo, centrandose na figura do professor e no acto de ensinar, tendo o aluno, ainda com muita frequência, um papel passivo e secundário. $\mathrm{Na}$ perspectiva tradicionalista (ainda hoje presente na prática pedagógica de muitos docentes) valoriza-se a capacidade de memorização e acumulação de informações em detrimento da compreensão, da capacidade de interrogar os conhecimentos adquiridos (RAPAZOTE, 2001) e 
do método de resolução de problemas inerente à construção do pensamento e ao acto de criar.

A teoria das representações sociais revela-se um excelente caminho para conhecer aspectos psicossociais em diferentes áreas do conhecimento. Neste estudo, ela possibilitou o entendimento das representações sociais da criatividade no âmbito da disciplina de EV construídas por professores e alunos, na interface da dinâmica da sala de aula.

\section{REFERÊNCIAS BIBLIOGRÁFICAS}

BOUROCHE, Jean-Marie et SAPORTA, G. (1990), 'Lánalyse des données', Presses Universitaires de France.

CIBOIS, U. F. R. (1995), Tri-deux Mots, 1 disque-

te, versão 2.2, Paris: Sciences Sociales.

COLLINS, Mary Ann, e AMABILE, Teresa M. (1999), “Motivation and Creativity", in STERNBERG, Robert J., 'Handbook of creativity', Cambridge University Press, pp. 297-312.

CSIKSZENTMIHALYI, Mihaly (2002), 'Fluir', Relógio D’Água Editores. DOISE, Willem e et al (1992), 'Représentations sociales et analyses de données', Presses Universitaires de Grenoble.

FRYER, Marilyn (1999), 'Creative Teaching and Learning', Paul ChapmanPuplishing Ltd, London.

GILLY, Michel (1997), "Les Représentations sociales dans le champ éducatif", in JODELET, Denise, 'Les représentations sociales', PUF, Paris, 5 a Ed..

JODELET, Denise (1997), 'Les représentations sociales', PUF, 5ํㅡㄹ..

MARTINS, Vitor M. T. (2000), 'Para uma pedago-

gia da criatividade', Edições Asa, Porto.

MOSCOVICI, Serge (1978), 'A Representação Social da Psicanálise', Rio de Janeiro, Zahar.

PINTO, Alexandra Marques (2000), 'Burnout profissional em professores portugueses: representações sociais, incidência e preditores', Dissertação de Doutoramento em Psicologia, Faculdade de Psicologia e Ciências da Educação da Universidade de Lisboa.

RAPAZOTE, Pedro (2001), “Criatividade no meio escolar”, in PATRÍCIO, Manuel Ferreira, 'Escola, Aprendizagem e Criatividade', Colecção Mundo de Saberes, Porto Editora, pp. 211-220.

SLABBERT, Johannes A. (1994), "Creativity in Education Revisited: Reflection in Aid of Progression", in The Journal of Creative Behavior, Vol. 28, №1, First Quarter, pp. 60-69.

SOUSA, Fernando Cardoso, A_CRIATIVIDADE_FORMACAO-PROFESSORES,
http://www.fbcriativo.org.br/procria/artigos/A_CRIATIVIDADE_FORMACAO-PROFESSORES.htm, (consulta em 11/10/2003)

VALA, Jorge e MONTEIRO, M. Benedicta (2002), 'Psicologia Social', Edição Fundação Calouste Gulbenkian, 5a Edição.

VIEIRA, Tânia Sardinha (2004), 'Representações sociais sobre criatividade construídas por professores e alunos no âmbito da disciplina de Educação Visual', Dissertação de Mestrado em Família e Sistemas Sociais, Instituto Superior Miguel Torga de Coimbra. 